\title{
Ruy Fausto, remando contra a maré
}

\author{
Ruy Fausto, against the current
}

\author{
Cicero Araujo \\ craraujo@usp.br \\ (Universidade de São Paulo, São Paulo, Brasil)
}

\begin{abstract}
Resumo: 0 artigo faz alguns apontamentos sobre o percurso de Ruy Fausto como intelectual público e suas relações com a esquerda. Destacam-se seu reexame da crítica de Marx ao capitalismo, a análise dos totalitarismos do século XX, assim como da social-democracia europeia, e a crítica da esquerda brasileira e dos governos do PT. 0 texto sugere uma camada adicional de interpretação do pensamento filosófico de Ruy Fausto, indicando como as matérias políticas ocuparam o centro de sua visão do mundo.
\end{abstract}

Palavras-chave: Ruy Fausto e a esquerda; Marxismo; Crítica do capitalismo; Totalitarismo; Democracia.
Abstract: The article makes some remarks about Ruy Fausto's trajectory as a public intellectual and his relationship with the Left. It stresses his reexamination of Marx's critical approach to capitalism, the analysis of the twentieth-century totalitarianisms as well as the European Social Democracy, and his criticism of the Brazilian Left and the PT governments. The article suggests an additional layer of interpretation to Ruy Fausto's philosophical thought, pointing out how the political issues were at the core of his worldview.

Keywords: Ruy Fausto and the Left; Marxism; Critique of capitalism; Totalitarianism; Democracy.

Remar contra a maré: nada exemplifica melhor essa imagem do que a posição de Ruy Fausto como intelectual de esquerda.

Em algum momento, nell mezzo del cammin de sua vida, ele atinou que a crítica do capitalismo era insuficiente para compreender a dominação social em nosso tempo. "Radicalmente insuficiente", disse certa vez. Pensador ele mesmo na chave crítica, jamais duvidou que o capitalismo fosse uma das peças centrais do quebra-cabeça. Porém, conforme foi juntando outras peças do século XX para fazer um balanço, deu-se conta de que a fixação exclusiva na crítica do capitalismo acabava deixando muitas perguntas sem resposta. E, mais importante, gerava um efeito político paralisante, ao bloquear uma interpelação mais funda (radical) dos problemas que a própria esquerda deveria enfrentar, se quisesse voltar a credenciarse como uma alternativa para o futuro do Brasil e do mundo. 
Ruy nunca tratava com superficialidade os assuntos que pautava em sua agenda de reflexão. Para começar, de crítica do capitalismo ele sabia muito, tendo se tornado um dos principais estudiosos brasileiros (se não o maior) da obra de Marx e da tradição marxista, justamente a tradição que levou mais longe essa empreitada. Ao que somava uma preocupação especial com a política, não apenas teórica, mas existencial, adquirida desde a juventude, o que dava uma tremenda vivacidade a suas elaborações. Por isso, mantinha-se muito bem informado sobre os acontecimentos correntes, além do interesse e enorme gosto pelo estudo da história, especialmente daqueles tempos e lugares que considerava mais relevantes para atritar com sua reflexão filosófica. Essas diferentes dimensões, ao contrário de cindir sua vida em demandas opostas, existiam dentro dele como parceiras inseparáveis.

Não tenho como fazer jus, neste breve artigo, à sutileza e às nuances de todos os tópicos que importam para compreender seu percurso como intelectual público. Vou me limitar a fazer alguns apontamentos sobre suas relações com a esquerda, no que diz respeito ao debate teórico e a certas questões práticas, misturando remissões à sua obra escrita mais recente - sobre a qual tenho maior familiaridade com lembranças de nossas conversas. Estas últimas, é claro, nem de longe equivalem ao rigor e complexidade do texto escrito; evoco-as apenas para dizer algo sobre o ser profundamente político que ele sempre foi, a sugerir, talvez, uma camada adicional de sentido a seu pensamento.

\section{O papel da crítica e alguns "pontos cegos" do marxismo}

Sabemos que a história da esquerda mundial é a história de uma família extensa, muito variada e de fronteiras fluidas, a ponto de tornar sua própria identidade matéria controversa. E também uma história oscilante, com altos e baixos. ${ }^{1}$ Acompanhando essas oscilações, por diversas vezes se tentou ensaiar seu funeral. Contudo, por diversas vezes, igualmente, se chegou à conclusão de que as notícias de sua morte eram prematuras... como diria o Marx comediante. E isso, suponho, menos por uma teimosia indiferente aos reveses e a uma inóspita realidade, do que pela capacidade de aprender com ambos e se renovar.

Forças sociais contestatórias sempre haverão de existir como resultado da própria dureza da dominação social. Mas elas não estão fadadas, apenas porque contestam, a se transformar numa opção política crível e desejável. Neste ponto é preciso reconhecer que a direita - uma família tão heterogênea quanto a esquerda - também se mostrou capaz de se adequar aos tempos e até aparecer, em algumas de suas vertentes pelo menos, como uma opção de rebeldia e protesto. Assim, não

1 Sobre o sentido, a validade e os limites contemporâneos da distinção esquerda/direita, ver Fausto $(2011 ; 2012)$. 
está escrito nas estrelas que a alternativa a uma certa forma de dominação seja, necessariamente, uma empreitada emancipatória. Este o primeiro artigo de fé de Ruy Fausto.

Segue-se daí uma certa maneira de compreender a crítica a partir da esquerda, que não se contente apenas em expressar o inconformismo com a dominação social. Ela impõe o desafio de vir acompanhada de um juízo reflexivo que interpele alternativas frustradas, alternativas a essas alternativas e modos de as articular nas lutas do presente. ${ }^{2}$ Portanto, a crítica não significa apenas pensar, mas pensar com consequência; digo, a consequência que é filha de um senso de responsabilidade pelo que se pensa e se fala, aquilo que opõe a crítica à pura e simples leviandade e the providencia uma espécie de âncora moral. Este o segundo artigo de fé de nosso amigo.

Mas a responsabilidade também carrega um lastro político. A crítica de esquerda não se basta como um desencargo de consciência solitário, como se lhe fosse suficiente dizer "eu bem que avisei...". Trata-se, agora, da consequência que se compromete, ao irradiar seu incômodo, a modificar o estado de ânimo da sociedade, como que extrovertendo aquela perturbação interior que leva a consciência moral a despertar. No fundo, é um apelo aos outros, um pedido de ajuda ao mundo, ainda que na forma de um pensamento crispado. Fazer a crítica é um fazer coletivo - ou assim deve ser, para que tenha efeito político. Este era seu terceiro artigo de fé.

Notem, todavia, o “contrato” de mútua responsabilidade implícito nele: um compromisso recíproco de dar e receber a crítica com suas respectivas consequências, visando justamente a constituir um campo de ação comum. Esse talvez o passo mais difícil, porque qualifica a aliança a ser feita, obrigando-a a transcender relações privadas com vistas a plasmar-se num projeto público. Público sim, mas feito por pessoas de carne e osso, que investem seus nomes numa trama que as expõem duplamente, tanto ao fazer quanto ao receber a crítica. Trama absolutamente necessária, mas nem sempre agradável. Não obstante o ônus que lhe trazia o estilo incisivo da crítica - em especial quando exigia colocá-la acima das amizades pessoais -, Ruy buscava levar os termos desse compromisso ao pé da letra.

Mas em que sentido essas observações remetem ao conteúdo mesmo da discussão, a começar o debate teórico que travou? Aqui é preciso falar um pouco de suas relações com o marxismo e com o próprio pensamento de Marx. O rompimento de Ruy com essa linhagem intelectual, que considerava a mais influente dentro da esquerda desde o final do século XIX, não foi um raio em céu azul, fruto de uma divergência puramente especulativa e abstrata. Decorria, isso sim, do teste histórico a que ela se submeteu, em particular ao longo do século XX. Assim mesmo, Ruy manteve com o pensamento de Marx uma posição de respeito, conhecendo-a, como conhecia,

2 Cf. "O Zero e o Infinito". In: Fausto, 2007, pp.155-164. 
em toda sua densidade. Mais: sempre considerou sua crítica ao capitalismo um ponto de partida sólido. Ao longo de muitos anos, ele buscou a melhor leitura possível da obra e do legado do grande pensador alemão, tentando desvendar como a forma de seu discurso - herdada do idealismo alemão, em particular a dialética hegeliana - se entrelaçava com a matéria investigada: o caráter do trabalho assalariado, a forma sutil de exploração nele implicado, a mais-valia, a forma-mercadoria, o famoso "fetiche" que irradia nas relações sociais quando ela se generaliza e adquire um caráter abstrato, o capital como poder social, os “modos de produção”, etc.

Ruy achava que Marx estava fundamentalmente certo ao enxergar que o capitalismo carrega uma instabilidade estrutural, fundada na forma contraditória com que aciona suas engrenagens, sujeitando-o a crises recorrentes e, às vezes, devastadoras. E, em seu trabalho de desmistificar a aparência “quase natural" de seu domínio, achava também que ele forneceu à esquerda um roteiro poderoso para questionar esse domínio e buscar alternativas. Mas que alternativas? A pergunta remete à política, e foi justamente a partir daí que Ruy começou a puxar os fios soltos - ou melhor, como dizia, os “pontos cegos" - da perspectiva marxista.

$\mathrm{Na}$ verdade, esses pontos cegos já se insinuam na própria crítica do capitalismo, na medida em que ela instigava Marx a pensar que o pleno domínio desse modo de produção empurraria as sociedades para uma encruzilhada, afunilando as alternativas e descartando possíveis "desvios" de rota. No fim das contas, elas teriam que ou saltar para além do capitalismo, seguindo o caminho que conduziria a uma existência emancipada (o comunismo), ou rumar para o completo desastre. Marx estava tão seguro de que o mecanismo contraditório da dinâmica capitalista levaria inexoravelmente a essa bifurcação fundamental - e só a ela -, que não se preocupou muito em fazer antecipações teóricas sobre a forma política do caminho anticapitalista. Uma vez golpeado o velho modo de produção e lançadas as bases do novo, tudo o mais haveria de seguir como simples consequência. Por isso, quando lhe veio a ideia da “ditadura do proletariado" como meio de enfrentar a previsível resistência das classes privilegiadas, pouca atenção deu às objeções de seu adversário anarquista Mikhail Bakunin, que alertava para a ameaça autocrática implícita no termo "ditadura", preferindo fixar-se unicamente em sua função de servir os interesses da classe social emancipadora. Quanto ao completo desastre, ficava como um tapa-buraco para o impensável ou, nas palavras de Ruy, um substituto para algo "mais ou menos da ordem do nada". ${ }^{3}$

Por que essas questões configuram pontos cegos? É claro que a resposta tem um lastro histórico: a experiência do século XX sugere que as contradições do capitalismo empurram as sociedades não para uma bifurcação, mas para um leque mais amplo

3 Cf. "Sobre a política de Marx" e "Acertos e Dificuldades do Manifesto Comunista". In: Fausto, 2007, pp.33-50 e pp.51-65. 
de alternativas, sem excluir o desastre, mas que agora precisava ser pensado. Da constatação histórica é possível, no entanto, passar para uma reflexão de alcance mais teórico. No caso de Ruy, significou passar para o reexame da própria crítica do capitalismo - fazer "a crítica da crítica", digamos assim. ${ }^{4}$

A percepção, em sua obra madura, de que o capital configura um poder cada vez mais abrangente e autonomizado, isto é, abstraído de qualquer finalidade exterior ao movimento mesmo de sua autovalorização, fez Marx pensar que estava lidando não apenas com um regime econômico, mas com um todo social - eis o ponto da categoria "modo de produção" - fechado em si mesmo, uma vez que, em seu desenvolvimento, cada uma de suas partes vai se soldando a todas as outras até não poderem mais ser separadas. Um sistema autocontraditório e, ao mesmo tempo, profundamente integrado. Por isso concluiu que seria impossível ("utópico") tentar se desfazer de uma delas sem também se desfazer das demais. Sua perspectiva de revolução social reflete esse ponto de vista: a única alternativa "realista" seria mudar tudo - da forma da propriedade ao trabalho assalariado, do mercado ao dinheiro, da fábrica ao Estado -, ainda que isso tivesse que tomar um tempo indefinido até que se completasse, ou seja, um período de transição entre o capitalismo e o comunismo, a que chamou de "socialismo".

Por outro lado, sua visão do capitalismo como um sistema social assim fechado se traduziu numa teoria da história na qual os futuros possíveis também iam se fechando até a bifurcação acima referida, na qual a alternativa anticapitalista só poderia seguir uma direção: o progresso da humanidade. Não the ocorreu que essa alternativa também pudesse envolver uma regressão histórica, um novo tipo de dominação social, inédito - a dominação totalitária, de que falaremos a seguir -, que derivasse do próprio esforço de superar o capitalismo. Daí não ter se importado em elaborar o problema da forma política dessa superação. Primeiro ponto cego.

Por outro lado, a perspectiva de mudar tudo (o comunismo) flagrava um resquício da herança iluminista ou, pelo menos, de uma certa herança iluminista, que apostava no advento de uma sociedade plenamente transparente. Marx pensava estar superando o "utopismo" iluminista - ainda presente, segundo ele, na esquerda hegeliana - ao pretender ir além da crítica que fosse fundada apenas no bom uso da razão, como se a dominação social pudesse ser reduzida a uma simples dominação espiritual, a uma opacidade ou intransparência da ordem do intelecto, tão bem exemplificado na crença religiosa. Marx, ao contrário, considerava que essa opacidade resultava da própria trama do fazer social e que mesmo uma sociedade emancipada da religião e regida apenas por interesses materiais - algo que o capitalismo mesmo se encarregava de promover - continuaria dominada por uma espécie de

4 Os apontamentos a seguir buscam condensar um argumento muito mais fino e sinuoso do que posso apresentar aqui. Cf. Fausto, 2017, Cap. II, espec. pp.37-48; e Fausto, 1987, Cap. I. 
"encantamento" sutil, traduzido por ele na figura do fetiche da mercadoria. Para superar essa forma "superior” de superstição, não bastava a crítica de uma razão esclarecida - que até poderia resultar numa ilusão de segunda ordem (a "ideologia”) -, mas seria preciso fazer a crítica prática, a crítica advinda de um fazer alternativo, contra o fazer social dominante.

Ruy, sem dúvida, gostava da visão de que o fetiche da mercadoria constitui uma abstração prática, social, e não uma simples ficção da consciência. Mas daí a pensar que sua crítica prática a essa abstração, através do impulso revolucionário e ao longo da transição socialista, pudesse limpar toda a opacidade das relações sociais, vai uma grande distância. Ainda que mudando brilhantemente seus termos, Marx mantinha, no fundo, essa meta aufklärer. Porém, mais importante: mantinha sua antropologia implícita, de uma “natureza” humana de tal modo plástica que nada nela poderia constituir obstáculo à intervenção do fazer crítico - no sentido de eliminar, por exemplo, os impulsos egóicos dessa natureza contrários ao projeto emancipador -, o que dava margem a um experimentalismo autoritário, se não brutal, junto com um novo tipo de mistificação, convertendo a crítica no seu oposto. Segundo ponto cego.

Por fim, o problema da relação entre o capitalismo e a forma política, que reflete uma dificuldade análoga ao da relação entre a empreitada pós-capitalista e a política. Sua concepção do capitalismo como modo de produção, isto é, como um todo social no qual as partes estão intimamente solidárias entre si, induziu-o a subsumir todo e qualquer elemento da política - o regime político e a forma do Estado - a funções de dominação social. Isso, a despeito de supor que o capitalismo é movido por uma contradição interna, que no fundamental, porém, estaria situada em outro lugar, na "casa das máquinas" da vida material. Se alguma forma política emergisse no interior do sistema, mas em contradição com ele, como durante um certo período imaginou fosse o caso da democracia, esta haveria de conduzir a sociedade para fora do capitalismo e, portanto, para a revolução. Exceto nesse caso, a democracia, tal como a forma jurídica do contrato, não passaria de uma ilusão de liberdade e igualdade, nada mais. Não estava em seu horizonte a viabilidade de uma coexistência contraditória real de democracia e capitalismo. Terceiro ponto cego.

\section{Totalitarismos, de direita e de esquerda}

Em anos mais recentes, Ruy Fausto debruçou-se sobre o problema de pensar, com base na história do século XX, o destino das revoluções e dos regimes políticos e sociais delas resultantes. Interpelação fundamental, uma vez que "revolução social" era o termo que talvez melhor resumia o projeto emancipatório da esquerda no início desse período. Como salientado antes, Ruy se viu convencido de que os regimes 
comunistas surgidos dessas revoluções mostravam cabalmente que alternativas anticapitalistas, ao contrário do esperado, poderiam tornar-se terríveis regressões históricas. O balanço do desempenho da esquerda no período, portanto, não é nada positivo.

Não que a direita e, de modo geral, os defensores da alternativa capitalista, tenham se saído melhor. O século começou com a catástrofe representada pela Primeira Guerra Mundial, talvez a origem comum de todas as desventuras posteriores, resultado ela mesma dos desdobramentos do capitalismo europeu nos quarenta ou cinquenta anos antecedentes, marcados pela competição imperialista. Contudo, mesmo aí é preciso admitir certa cumplicidade da esquerda, no caso a esquerda não revolucionária, a social-democracia europeia, que majoritariamente emprestou seu apoio à guerra e acabou caindo num longo descrédito. Essa decisão histórica, que Ruy qualificava como "quase criminosa", praticamente entregou a iniciativa da luta política, no período crucial que se seguiu, para uma esquerda mais propensa a perder-se nos pontos cegos do marxismo acima assinalados. ${ }^{5}$

Dois eventos, quase concomitantes, e que marcarão o século $X X$, seguem-se diretamente da Primeira Guerra: a Revolução Russa e a emergência do fascismo a partir da Itália. Embora derivados de uma causa comum, a apreciação que Ruy faz deles, ao contrário de certos historiadores conservadores, não é a mesma: o primeiro era, em princípio, um evento auspicioso, na medida em que derrubava o último baluarte do absolutismo na Europa, o império czarista; enquanto o segundo já representava o início da grande regressão histórica que vai desembocar na ascensão do nazismo e na Segunda Guerra Mundial. A história da Revolução Russa é mais sinuosa, uma vez que história de esperança que mais à frente se descarrilha, conforme o bolchevismo assume a liderança da revolução e inicia o erguimento de um novo poder estatal. Posteriormente, esse novo poder, já autoritário, envereda para a regressão pura e simples, na forma do regime stalinista. ${ }^{6}$

Em virtude de certos aspectos exteriores comuns, e da necessidade de marcar a absoluta novidade histórica que significavam, Ruy adotou, seguindo certos analistas, o termo "totalitarismo" para nomear ambas as regressões, uma a partir da direita e a outra a partir da esquerda. Como uma aproximação genérica aos dois objetos, o totalitarismo servia-lhe para assinalar o último ponto da escala de um processo de radicalização e disseminação da violência, que começava com a instalação de ditaduras de um partido revolucionário - um de extrema direita e outro de extrema esquerda - até se tornarem regimes autocráticos tout court, sustentados no terror de massa recorrente, nos campos de concentração e em práticas de extermínio de populações. Ainda que o regime stalinista (e depois o regime maoísta) não tenha

5 Sobre a trajetória da social-democracia europeia e seus percalços, ver Fausto, 2007, pp..224 e ss. 6 Para um balanço da Revolução Russa, ver Fausto, 2017a, Caps. IV e V. 
chegado ao ponto de almejar o extermínio sistemático e completo de uma "raça" determinada, como fez o nazismo, isso não quer dizer que houvesse sido menos devastador em sua fúria para prender ou eliminar uma quantidade colossal de pessoas, cuja característica comum, aliás, era o de não representarem absolutamente nenhuma ameaça ao poder estabelecido.

A despeito das semelhanças em termos de modus operandi, Ruy destacava diferenças, que considerava essenciais, entre o totalitarismo de esquerda e o de direita, tanto em relação a sua "pré-história" (a questão das origens) quanto em relação às práticas de legitimação e ao discurso ideológico. Essa distinção provinha de seu diálogo com outras análises dos regimes totalitários, das quais recebera forte influência, mas que tendiam a enfatizar mais suas continuidades do que descontinuidades. É o caso da análise clássica de Hannah Arendt, que ele apreciava muito, mas que não conseguia explicar as "origens" do stalinismo com o mesmo fôlego e perspicácia com que retraçara as "origens" do nazismo. Evidentemente, ele tinha um interesse especial pelo estudo das raízes do totalitarismo de esquerda.

Também por conta do debate político que o assunto suscitava, importavathe menos providenciar uma explicação sociológica do que uma compreensão do complexo jogo de ideias que poderiam ter contribuído, ainda que até certo ponto involuntariamente, para a introdução de um poder totalitário a partir da esquerda. Já buscamos indicá-lo brevemente aqui, com a noção de "pontos cegos" do pensamento de Marx. Isso não quer dizer, nem de longe, que o regime stalinista (ou o maoísta, que é uma espécie de continuação ${ }^{7}$ ) tivesse sido emanação direta de sua teoria do socialismo e do comunismo. Mas também não significa isentá-la completamente de equívocos e faltas de precaução, os quais poderiam facilmente resultar em apropriações oportunísticas, até chegar à completa inversão de seu sentido. Entre o marxismo original e a prática totalitária, há uma série de passagens indiretas, que ele tratou de identificar em seu próprio esforço de fazer uma "pré-história" dos regimes comunistas.

Assim, entram nessas passagens a história peculiar da esquerda russa, o pensamento de Lênin, o advento do bolchevismo e suas relações ancestrais com a tradição jacobina e do terror revolucionário, a apropriação autoritária, pelo leninismo, das energias democráticas e progressistas da Revolução Russa, etc. No processo, a conversão da figura da "ditadura do proletariado", como havia previsto Bakunin, em ditadura do partido e finalmente em ditadura do autocrata ou déspota. Note-se, mais uma vez, a ênfase na análise das ideias e em suas fatídicas "interversões" - figura do discurso dialético frequentemente empregada por Ruy para indicar a passagem histórica de termos opostos (ou, tal como ele a descrevia, "a passagem do oposto ao oposto"): por exemplo, como, do igualitarismo que é posto no discurso original

7 Sobre a Revolução Chinesa e o regime maoísta, ver Fausto, 2017a, Cap.VI. 
do regime revolucionário, e que depois vai “calçar” ideologicamente os regimes comunistas, passa-se, através da negação da liberdade, para seu exato oposto (a não-igualdade). É nessa passagem essencial que o totalitarismo de esquerda força sua entrada, quase que imperceptivelmente, no plano das ideias e valores originais de esquerda - daí nosso autor chamá-lo também de "totalitarismo igualitarista" -, do qual distingue o "totalitarismo não-igualitário", de direita, que, por negar de partida o valor da igualdade e endossar a teoria da superioridade racial, se impõe sem precisar realizar a interversão. ${ }^{8}$

Enfatizar as ideias e, ao mesmo tempo, evitar abordagens "sociologizantes" (como ele as chamava) do fracasso do socialismo soviético e sua reversão numa forma inédita de despotismo era também um modo de afastar explicações marxistas ad-hoc que procuravam estender para essa experiência a crítica do capitalismo. Quero dizer, explicações como a seguinte: que o socialismo soviético era na verdade uma forma disfarçada de capitalismo de Estado, fruto do próprio atraso do desenvolvimento econômico na Rússia e do desafortunado fracasso da revolução proletária nos países capitalistas mais avançados. Ruy via nessas explicações uma tentativa de manter a todo custo o mesmíssimo quadro de ideias que, ao fim e ao cabo, teimava em impedir que a esquerda predominante encarasse de frente os pontos cegos da fonte original e então tirasse as devidas consequências. Não se tratava, portanto, de contrapor explicações “idealistas” a explicações “materialistas”, mas de renovar o projeto, através do embate de ideias orientadoras da conduta política - que, como indicado no início deste artigo, sempre diz respeito a uma tomada de posição crítica, ancorada nas possíveis alternativas.

\section{Democracia, capitalismo e certas armadilhas}

Voltemos ao problema da junção entre democracia e capitalismo. Como já destacado, Ruy Fausto a via como uma junção contraditória, uma espécie de interpenetração de opostos, para a qual empregava a expressão “democracia capitalista". ${ }^{9}$ Esta poderia significar tanto um freio aos valores de igualdade e liberdade - que o polo democrático enseja -, quanto um freio à dominação do capital. Por um lado, abria a possibilidade de introduzir mudanças progressistas no interior do capitalismo, como havia ocorrido nos países europeus ocidentais do pós-guerra. ${ }^{10}$

8 Sobre essas passagens da "pré-história", até a história propriamente dita dos regimes totalitários de esquerda, e sobre sua diferença com o totalitarismo de direita, ver Fausto, 2017a, Caps.II e III.

9 Sobre esse conceito, ver, entre outros, Fausto, 2007, pp.18 e ss.

10 Sua perspectiva de longo prazo, no entanto, era de ir além da democracia capitalista, o que demandaria um regime político e social de neutralização do domínio do capital, que Ruy chamava de "socialismo democrático" ou "democracia radical". Sobre a ideia da neutralização do poder do capital e a necessidade de uma nova crítica da economia política para fundamentá-la, ver Fausto, 2017b, pp.95-104. 
Mas, por outro lado, também abria um campo de armadilhas, todas elas relacionadas a tendências de acomodação com o sistema dominante.

Atesta os perigos da acomodação a própria trajetória da social-democracia europeia. A começar, como vimos, pela rendição ao belicismo na Primeira Guerra Mundial. É verdade que a social-democracia viveu, mais tarde, seu grande momento, durante os chamados "trinta anos gloriosos", após 1945. E, contudo, voltou a cair nas armadilhas da acomodação ao longo do período de predomínio neoliberal, até chegar a um quase completo descrédito nos últimos anos, como exemplificado pelo melancólico governo do socialista François Hollande, na França.

Mas Ruy se preocupava especialmente com o destino da esquerda brasileira, a partir da ascensão de Lula e do Partido dos Trabalhadores ao governo nacional. Foi um momento de grande esperança, em vista da trajetória anterior do PT, de forte vínculo com os movimentos sociais, ativa participação na reconstrução democrática do país e luta contra as iniquidades do capitalismo brasileiro. Com base em seu conhecimento da experiência social-democrata e dos impasses da política brasileira no período democrático anterior (1946-1964), nosso amigo buscou fazer advertências a respeito daquelas armadilhas, antes mesmo da ascensão de Lula à presidência da república. ${ }^{11}$

Duas questões se destacam. Aprimeira diz respeito às alianças, tanto as eleitorais quanto as de sustentação do governo. Não é uma questão elementar, especialmente em se tratando de um país como o Brasil, tão extenso e heterogêneo do ponto de vista regional, e com pouca tradição de partidos com consistência programática. Seria, talvez, uma questão menos problemática se as correntes políticas visando ao poder estatal pretendessem apenas administrar o status quo. Mas, para correntes de esquerda que queiram de fato pôr em andamento uma plataforma de reformas econômicas e sociais progressistas, o desafio é bem outro. As alianças têm de ser suficientemente amplas para garantir a aprovação de leis no Congresso, como o exige um regime democrático; e todavia consistentes do ponto de vista programático, para não minar de partida seu ímpeto reformista. O problema de fundo, na verdade, é como conciliar a transformação social, que dá sentido a uma política de esquerda, com as instituições e valores democráticos. E isso nos leva à segunda questão.

No passado, a dificuldade acima descrita predispôs boa parte da esquerda latino-americana a defender saídas rupturistas, o que impunha o emprego da violência como horizonte estratégico. Nas últimas décadas, conforme os países da região foram se democratizando, essa estratégia perdeu credibilidade. Vários partidos de esquerda começaram a crescer eleitoralmente e passaram a abraçar a ideia de um caminho de transformações pela via institucional. O PT foi um dos que mais tiveram

11 Sobre a esquerda brasileira, o PT e os governos de Lula e Dilma Rousseff, ver Fausto, 2009, Parte I, Cap.2; e Fausto, 2017b, Caps. 1 e 3. 
sucesso nessa rota, com ampliações sucessivas de suas bancadas parlamentares e do número de governos locais que administrava. Em 2002, para aumentar as chances de vitória na eleição presidencial, chegou mesmo a fazer um movimento em direção ao centro, tanto nas alianças quanto em sua plataforma. Gesto delicado e cheio de riscos, mas politicamente aceitável, se o partido pudesse negociar publicamente um programa reformista comum e - tão importante quanto isso - não arredasse o pé de certos princípios de conduta. Entre esses últimos, a orientação de jamais transigir com a corrupção.

Para Ruy, essa não era uma questão menor. A seu ver, a esquerda pouco tinha a ganhar se substituísse a tentação da violência revolucionária (entendida não como recurso de defesa, mas como forma "positiva" de luta) pela de usar o poder do dinheiro para promover as mudanças sociais desejadas. Equivaleria a fazer uma cesura inapropriada entre meios e fins, pela qual fins "bons ou corretos" poderiam ser obtidos através de meios "maus ou incorretos". Nos dois casos em tela, o da violência e o da corrupção, os meios empregados contaminariam irremediavelmente os fins almejados. Ambos acabariam desencadeando uma espécie de círculo vicioso: uma vez adotado esse caminho, seria muito difícil, se não impossível, sair dele. A conduta oposta poderia parecer moralista e até utópica, mas Ruy buscava fundá-la numa visão que considerava, ao contrário, a mais realista.

O ponto remete à importância de princípios éticos "transcendentais" não só na conduta pessoal, mas também na conduta política, que ele aprendeu a revalorizar no interior mesmo de sua crítica à crítica marxista do capitalismo. ${ }^{12}$ Não temos como aprofundar o assunto neste espaço, mas vale a pena pelo menos indicar o significado do termo "transcendental" nessa ponderação. Ocorre que a teoria da história dita "materialista" tende a pensar os sujeitos do drama da transformação social como simples suportes da posição de classe que venham a ter. De certa forma, a conduta pessoal ou coletiva é remetida à posição de classe, isto é, ao papel ou função que uma determinada classe social desempenha em diferentes épocas históricas: essa marcada "objetivação" do sujeito tende a animar uma visão da história em que nada escapa à imanência das forças impessoais que regem seu desdobramento. 0 que a faz secundarizar princípios como o da dignidade intrínseca do ser humano. Tais princípios só fariam sentido, isso sim, numa sociedade plenamente emancipada. Antes disso, operam como simples ilusões ou, mais grave ainda, como "ideologia", que de resto têm a função de retardar a marcha da história.

Sem desprezar a importância dos interesses objetivos de classe, Ruy buscou, em sua crítica, modos de restabelecer uma noção forte de sujeito político, na qual fizesse sentido pensá-lo como atuando, ao mesmo tempo, "dentro" e "fora" da

12 Cf. Fausto, 2009, pp.149-151; sobre a relação desse ponto com o tópico do "populismo de esquerda", que não discuti aqui, ver Fausto, 2017b, pp.29-39. 
história. E assim abrindo espaço para dar à sua prática uma dimensão transcendental. Nesta ponderação, haveria de apostar que na consciência do sujeito algo sempre escapa à objetivação, abrigando uma brecha para agir não apenas de acordo com fins dados, mas segundo princípios. Dessa forma, em vez de torná-la suspeita de uma consciência ilusória, Ruy passa a ver essa brecha como um atributo intrínseco ao sujeito que não é apenas suporte, mas que efetivamente age.

Por isso mesmo, o sujeito assim orientado jamais pode considerar trivial qualquer cesura de meios e fins. No mínimo, os princípios impõem limites ao emprego de meios, exatamente porque o sujeito que os abraça é levado a ponderar se suas consequências afetam a própria dignidade dos fins. ${ }^{13}$ Eis que a consciência moral sempre nos coloca a questão: vale a pena fazer assim ou assado? A pergunta pode até merecer diferentes respostas, dependendo das circunstâncias; o que não se pode fazer é desprezar sua interpelação, especialmente se ela afeta o destino de outros ou de muitos outros, como acontece nas decisões políticas.

Para além do aspecto estritamente ético, a corrupção suscita uma outra ponderação, a qual diz respeito diretamente ao caráter das "democracias capitalistas", a tensa interação entre democracia e capitalismo. Há dois modos pelos quais este último busca se desfazer do incômodo que representam os valores e as instituições democráticas: ou pela pura e simples eliminação do regime democrático, ou por sua neutralização. Em tempos neoliberais, a segunda estratégia foi a que prevaleceu. A neutralização significa substituir os recursos próprios da ação política - o embate público de ideias, o convencimento dos eleitores, a militância voluntária dos cidadãos em defesa de seus direitos e tantos outros - pelo poder acachapante do dinheiro. Isto é, reduzir o regime democrático a uma forma de "governo através do dinheiro". Valer-se do recurso da corrupção para promover as metas de um governo, por mais progressistas que elas sejam, implica na prática entrar no jogo dessa redução. Em termos puramente realistas, Ruy não via nenhuma chance de as forças de esquerda prevalecerem nesse terreno.

\section{Conclusão}

Ao longo de todo o tempo que, em sua vida, dedicou a alimentar o debate público, Ruy Fausto sempre se viu remando contra duas marés: a maré da esquerda dominante e a maré da direita dominante - esta última expressa, mais recentemente, no discurso neoliberal. Era, dizia, seu modo de rejeitar, no campo da política, o princípio do terceiro excluído. Ou seja, evitar a disjuntiva, quase sempre enganosa, do tipo "ou você está de um lado, ou está necessariamente do lado oposto" - a qual,

13 Haveria de incluir nesse campo de ponderações o desafio posto pela crise ecológica e os limites da objetivação da própria natureza. Sobre a questão ecológica, ver Fausto, 2017b, pp.39-45. 
no fundo, trabalha pelo abafamento da posição mais reflexiva e mais propícia ao adensamento de alternativas.

Enfim, cá estamos outra vez perante a crítica e a responsabilidade por suas consequências.

\section{Referências}

Fausto, R. (1987). Marx. Lógica e Política: Investigações para uma reconstituição do sentido da dialética. Tomo II. São Paulo: Brasiliense.

Fausto, R. (2007). A esquerda difícil: em torno do paradigma e do destino das revoluções do século XX e alguns outros temas. São Paulo: Perspectiva.

Fausto, R. (2009). Outro dia: intervenções, entrevistas, outros tempos. São Paulo: Perspectiva.

Fausto, R. (2011;2012). Esquerda/Direita: Em busca dos fundamentos, e reflexões críticas. Revista Fevereiro: Política, Teoria, Cultura n. 3 e 4, junho de 2011 e janeiro de 2012. Recuperado de: http://www.revistafevereiro.com/pag. php?r=04\&t=09 [acesso: 08.10.2021].

Fausto, R. (2017a). O Ciclo do Totalitarismo. São Paulo: Perspectiva.

Fausto, R. (2017b). Caminhos da esquerda: elementos para uma reconstrução. São Paulo: Companhia das Letras. 